\title{
Successful testing and treating of HIV/AIDS in Indonesia depends on the addiction treatment modality
}

This article was published in the following Dove Press journal:

Journal of Multidisciplinary Healthcare

13 December 2012

Number of times this article has been viewed

\author{
Shelly Iskandar ${ }^{1-3}$ \\ Cor AJ de Jong ${ }^{3}$ \\ Teddy Hidayat ${ }^{\prime}$ \\ Ike MP Siregar' \\ Tri H Achmad ${ }^{4}$ \\ Reinout van Crevel $^{5}$ \\ Andre van der Ven ${ }^{5}$ \\ 'Department of Psychiatry, \\ Padjadjaran University/Hasan Sadikin \\ Hospital, Bandung, Indonesia; ${ }^{2} \mathrm{Health}$ \\ Research Unit, Medical Faculty, \\ Padjadjaran Univervisity, ${ }^{3}$ Nijmegen \\ Institute for Scientist-Practitioners \\ in Addiction (NISPA), Nijmegen, \\ The Netherlands; ${ }^{4}$ Department of \\ Biochemistry, Faculty of Medicine, \\ Padjadjaran University/Hasan \\ Sadikin Hospital, Bandung, Indonesia; \\ ${ }^{5}$ Department of General Internal \\ Medicine and Nijmegen Institute for \\ Inflammation, Infection and Immunity, \\ Radboud University Nijmegen Medical \\ Centre, Nijmegen, The Netherlands
}

Correspondence: Shelly Iskandar Department of Psychiatric, Faculty of Medicine, Padjajaran University/ Hasan Sadikin Hospital, Jl. Pasirkaliki no 190 Bandung 40 I5I, Indonesia

Tel +62 2270720492

Fax +62 222033915

Email shelly_bdg@yahoo.com
Background: In many settings, people who inject drugs (PWID) have limited access to human immunodeficiency virus (HIV) care which is provided in several hospitals and primary health centers in big cities. Substance abuse treatment (SAT) can be used as the entry-point to HIV programs. The aim of this study is to describe the characteristics of the PWID who had accessed SAT and determine which SAT modality associates significantly with HIV programs.

Methods: PWID were recruited by respondent-driven sampling in an urban setting in Java, Indonesia and interviewed with the Addiction Severity Index (ASI), Blood-Borne Virus Transmission Risk Assessment Questionnaires, and Knowledge Questionnaire on HIV/AIDS. The information regarding the use of substance abuse treatment and HIV program were based on questions in ASI.

Results: Seventy-seven percent of 210 PWID had accessed SAT at least once. PWID who had accessed a SAT modality reported more severe drug problems. The most widely used SAT were opioid substitution (57\%) and traditional/faith-based treatment (56\%). Accessing substitution treatment (adjusted odds ratio $[\mathrm{OR}]=5.8 ; 95 \%$ confidence interval $[\mathrm{CI}]: 2.5-13.9$ ) or residential drug-free treatment (adjusted $\mathrm{OR}=3.7 ; 95 \% \mathrm{CI}$ : 1.4-9.7) was significantly associated with HIV testing, whereas accessing substitution treatment (adjusted OR $=3.8 ; 95 \% \mathrm{CI}: 1.9-7.5$ ) or other medical services (adjusted OR $=3.1 ; 95 \%$ CI: $1.1-8.7$ ) was significantly associated with HIV treatment. There was no significant association between accessing traditional/faith-based treatment and HIV testing and treatment.

Conclusion: Efforts should be made to link HIV services with traditional/faith-based treatment to increase the coverage of HIV programs.

Keywords: HIV, addiction treatment, access to care, people who inject drugs

\section{Introduction}

The number of people who inject drugs (PWID) in 2007 worldwide was estimated to be 15.9 million, and approximately 3 million of them were infected with human immunodeficiency virus (HIV). ${ }^{1}$ Injecting drug use is also estimated to account for $30 \%$ of all new HIV infections outside sub-Saharan Africa. ${ }^{2}$ Apart from HIV, PWID are often affected by co-occurring problems such as other infectious diseases including hepatitis and tuberculosis, psychiatric problems, and other substance use disorders. PWID with these comorbidities are likely to engage in high-risk behaviors, and when untreated, continue to fuel the HIV epidemic. ${ }^{3}$ In addition, engagement in high-risk sexual behavior may lead to HIV spreading further into the general community. ${ }^{4}$ Antiretroviral (ARV) treatment significantly reduces HIV transmission, ${ }^{5}$ however different studies showed that PWID still had very limited access to HIV care. ${ }^{6,7}$ 
Clinicians and policymakers have underlined the crucial role of evidence-based substance abuse treatment (SAT) in HIV prevention and care programs. ${ }^{8,9}$ Globally, many SAT modalities, especially methadone therapy, do have the capacity of offering counseling and testing for HIV, providing interventions to reduce risk behavior, referring patients for HIV treatment, or prescribing and monitoring HIV treatment. ${ }^{8} 9$ However, PWID often have poor access to the regular SAT since drug use is illegal and highly stigmatized. ${ }^{10}$ PWID and their families often hide the drug-related problems and avoid the regular SAT, as this may further increase the social ostracism faced by the families. Because of unawareness or absence of easily accessible treatment, particularly in resource-limited countries, PWID and family members may prefer to approach alternative service providers such as faith-based treatment. ${ }^{11}$

In traditional or faith-based treatment, it is believed that drug addiction is mostly due to a lack of religiosity. Most of the traditional or faith-based therapies usually occur in residential facilities. The treatment approach obligates the clients to pray and read spiritual/religious books in most of their spare time. Some therapies emphasize the important role of remembrance of God because only by remembrance of God will the self be always aware and alert about the real purpose of life. ${ }^{12}$

In Indonesia, injecting drug use increased dramatically in the late 1990s, acting as the main force driving the HIVepidemic. Among the general population, the prevalence of HIV-infection is still low $(0.3 \%)$ but it is $50 \%$ or higher among PWID. ${ }^{13}$ PWID in Indonesia engage in high-risk behavior, both through needle sharing and unprotected sex. ${ }^{14,15}$ In response to the problems of drug use and HIV, specific intervention programs have been developed in Indonesia. Methadone maintenance treatments (MMT) are developed in big cities and first-line ARV drugs are provided for free in hospitals and primary health centers in big cities. The start of the services was funded by government and donor organizations; some services are still subsidized by the government. In Bandung (Hasan Sadikin Hospital), opioid substitution treatment (methadone or buprenorphine) and HIV services have been available at the methadone clinic since 2009. ${ }^{16}$ Integration of opioid substitution treatment and ARV in other settings have not been fully established although at some places both services are provided in the same building or hospital. ${ }^{17}$ Only $30 \%$ of all Indonesian addiction professionals consider addiction as a brain disease, whereas about $70 \%$ consider faith-based and long-term residential treatments to be the most appropriate treatment modalities. ${ }^{18}$
Furthermore, although there is a significant number of traditional/faith-based treatments, there are only few of them which have collaboration with conventional medical services such as HIV test and treatment.

The coverage of these HIV intervention programs remains very low: only $1 \%$ of the PWID are currently enrolled in MMT programs; and only $6 \%$ of the HIV-infected PWID have been treated with ARV drugs. ${ }^{7}$ The aim of the present study was to investigate possible explanations of the low coverage of HIV testing in PWID by comparing PWID who had accessed SAT and those who had not. Furthermore, the types of SAT accessed by PWID was explored and determined to reveal which SAT was associated with uptake of HIV testing and HIV treatment.

\section{Methods}

\section{Participants}

From June to September 2008, 210 PWID were recruited from all subdistricts in Bandung, the capital of West Java and the epicenter of an epidemic of injecting drug use in Indonesia. Respondent-driven sampling (RDS), a form of peer recruitment, was used for recruitment of PWID from the community. ${ }^{19}$ RDS combines "snowball sampling" with a mathematical model that weights the sample to compensate for the fact that the sample was collected in a nonrandom way. ${ }^{19}$ All PWID who passed this screening then provided informed consent. The study complied with the Declaration of Helsinki and was approved by the regional medical-ethical committee (87/FKUP-RSHS/KEPK/Kep./EC/2008).

\section{Assessment}

The interview was conducted at the community health center by trained interviewers who assured all participants that their anonymity would be strictly maintained. The interviewers used three validated questionnaires: the European Addiction Severity Index (EuropASI), Blood-Borne Virus Transmission Risk Assessment Questionnaires (BBV-TRAQ), and Knowledge Questionnaire on HIV/AIDS.

The EuropASI is an adaptation of the Addiction Severity Index (ASI) 5th version. ASI has shown excellent reliability and validity across a range of types of patients and treatment settings in many countries. ${ }^{20}$ For the translation into Bahasa Indonesia, World Health Organization (WHO) translation procedures were used. ${ }^{21}$ The ASI is a semistructured interview which takes about 1 hour, and covers medical status, including questions about HIV testing and treatment, employment/support status, drug/alcohol use, legal status, family/social relationships, and psychiatric problems. 
Each of these areas is examined individually by collecting information regarding the frequency, duration, and severity of symptoms of problems both historically over the course of the patient's lifetime, and during the 30 days prior to the interview. ${ }^{22,23}$ In order to measure addiction severity in a more objective way, the selective combination of items from each of the ASI problem areas were used to calculate the composite score, which can be used as a general measure of patient status in each area. These measures have shown reliability and validity in several settings. ${ }^{24}$ The information regarding the use of substance abuse treatment and HIV program were based on questions in EuropASI. They were asked whether in their lifetime they had ever had HIV testing and treatment or not, and ever accessed any type of SAT or not, how many and which kind of SAT they had accessed.

The BBV-TRAQ questionnaire assesses how often injecting drug users participate in specific injecting, sexual, and other risk-practices that may expose them to blood-borne viruses. The instrument consists of 34 questions divided into three subscales which measure frequency of current risk behavior related to blood-to-blood transfer (20 questions); sexual practices (eight questions); and other skin penetration activities (six questions) in the previous month. The administration time for the instrument is short (around 15 minutes), and it has shown good reliability and validity. ${ }^{25}$

Knowledge on HIV/AIDS was evaluated using a questionnaire, which included 10 questions that address three areas of HIV/AIDS knowledge: (a) general knowledge concerning HIV/AIDS; (b) knowledge concerning HIV transmission; and (c) knowledge of prevention. The number of correct responses for the total scale and for each subscale was computed and higher scores indicate more knowledge. The reliability was high (Cronbach's $\alpha=0.97) .^{26}$

\section{Data analysis and statistics}

Descriptive data were presented in terms of percentage, mean, and standard deviation. Data were analyzed inferentially for differences between those who had not accessed, and those who had accessed SAT in his/her lifetime. Pearson's chi-square was used for dichotomous data and the MannWhitney $U$ test for nonparametric continuous data. All tests were two-sided, with a $P$ value of 0.05 or less considered to indicate statistical significance. All subjects that have accessed SAT were included in a multivariate logistic regression analysis to identify which type of SAT was associated with HIV testing and HIV treatment. In the adjusted model, all types of substance abuse treatments were included as variables. Analyses were performed with SPSS software (version 15; IBM, Armonk, NY).

\section{Results}

A total of 210 PWID came from all subdistrict areas in Bandung, which indicates the representativeness of the sample. Seventy seven percent of them (161 PWID) had visited any type of SAT. Sociodemographic data did not differ between those who had not accessed SAT and those who had accessed SAT (Table 1). Almost all of them were male. The mean age was 28 years (standard deviation [SD], 4 years) and most participants had graduated from senior high school or higher education.

PWID from both groups had started using injecting drugs at a young age (18 years; SD, 3 years). Those who had accessed SAT had more severe drug problems compared to those who had never accessed SAT. This was indicated by a longer period of injecting drugs, higher prevalence of drug use in the last 30 days, more episodes of drug overdose, more cigarette smoking, and a higher drug composite score. Interestingly, alcohol problems were more frequent among those who had never accessed SAT.

Despite the high score on knowledge about HIV, especially in PWID who had already accessed SAT, 78\% of the respondents still engaged in risky behavior for HIV transmission. There were no differences in the percentage and frequency of injecting, sexual, and other risk-taking behaviors between the two groups. Those that had accessed SAT also did not differ with regard to the severity of medical and psychiatric conditions, nor in HIV prevalence rates.

Of all PWID, 75\% have been tested for HIV, and $60 \%$ of HIV-positive PWID subsequently received ARV treatment. Those who had accessed SAT were more likely to be tested for HIV ( $83 \%$ vs $48 \%$ ) and hepatitis C (64\% vs 44\%). The same trend found in HIV treatment (62\% vs $33 \%$ ). However, due to the small numbers, the difference on HIV treatment was not statistically significant. Psychiatric treatment was not frequently given since $95 \%$ of all patients experienced psychiatric problems yet only $30 \%$ received such treatment. Those accessing SAT were more often treated for psychiatric disorders (33\% vs $17 \%)$.

The most widely accessed SAT were substitution treatment $(56 \%)$ and traditional/faith-based treatment (57\%) (Table 2). On average, PWID reported five (range, 1-27) episodes of accessing SAT. Table 3 showed that accessing substitution or residential drug-free treatment increased the probability to be tested for HIV (odds ratio [OR] $=5.8 ; 95 \%$ confidence interval $[\mathrm{CI}]: 2.5-13.9)$ and $(\mathrm{OR}=3.7$; 95\% CI: 1.4-9.7), respectively. Accessing substitution treatment 
Table I The comparison of sociodemographic characteristics, drug use, medical, and psychiatric conditions of people who inject drugs who had never accessed and ever accessed substance abuse treatment

\begin{tabular}{|c|c|c|c|c|}
\hline \multirow[t]{2}{*}{ Characteristics } & \multicolumn{2}{|c|}{ Had accessed substance abuse treatment } & \multirow[t]{2}{*}{$\chi^{2} / U$} & \multirow[t]{2}{*}{$\mathbf{P}$} \\
\hline & No $(N=48)$ & Yes $(N=162)$ & & \\
\hline \multicolumn{5}{|l|}{ Sociodemographic characteristics } \\
\hline Male, N (\%) & $46(96)$ & I48 (9|) & 1.05 & 0.54 \\
\hline Age, mean (range, years) & $27(17-42)$ & $28(2 \mid-42)$ & 10.37 & 0.32 \\
\hline Education, $\mathrm{N}(\%)$ & & & 8.93 & 0.06 \\
\hline Junior high school or lower & $5(10)$ & $7(4)$ & & \\
\hline Senior high school & $40(84)$ & $124(77)$ & & \\
\hline Diploma or higher & $3(6)$ & $31(19)$ & & \\
\hline Marital status, N (\%) & & & 3.63 & 0.60 \\
\hline Married & $16(33)$ & $47(29)$ & & \\
\hline Widowed, separated, or divorced & $4(8)$ & $24(15)$ & & \\
\hline Never married & $28(59)$ & $91(56)$ & & \\
\hline Income from employment in the last 30 days & $969(1,730)$ & $1,191(2,639)$ & 0.87 & 0.59 \\
\hline \multicolumn{5}{|l|}{ (thousand rupiah), mean (SD) } \\
\hline \multicolumn{5}{|l|}{ Drug use } \\
\hline Age first injected drugs, mean (SD) & $18(4)$ & $18(3)$ & 6.07 & 0.34 \\
\hline Injected drugs in lifetime, mean (SD) & $5(4)$ & $8(4)$ & 0.27 & $<0.01$ \\
\hline Injected drugs in the last 30 days, $\mathrm{N}(\%)$ & $17(35)$ & $89(55)$ & 5.65 & 0.02 \\
\hline Overdose, N (\%) & II (23) & $88(54)$ & 14.66 & $<0.01$ \\
\hline Cigarettes smoked in the last 30 days, mean (SD) & $370(205)$ & $459(252)$ & 2.05 & 0.03 \\
\hline Drug composite score $(0-I)$, mean (SD) & $0.13(0.10)$ & $0.18(0.13)$ & 3.12 & 0.03 \\
\hline Alcohol composite score $(0-1)$, mean (SD) & $0.25(0.18)$ & $0.16(0.20)$ & 2.70 & $<0.01$ \\
\hline Risk behavior, N (\%) & $42(88)$ & $124(77)$ & 2.68 & 0.11 \\
\hline Injecting risk behavior (0-100), mean (SD) & $5(10)$ & $5(8)$ & 0.27 & 0.95 \\
\hline Sexual risk behavior $(0-40)$, mean (SD) & $2(3)$ & $3(5)$ & 6.30 & 0.23 \\
\hline Other risk behavior (0-30), mean (SD) & $3(4)$ & $2(3)$ & 0.06 & 0.26 \\
\hline Knowledge on HIV (0-I0), mean (SD) & $8(2)$ & $9(2)$ & 1.57 & 0.02 \\
\hline \multicolumn{5}{|l|}{ Medical condition } \\
\hline Have chronic problem, N (\%) & $24(50)$ & $64(40)$ & 1.68 & 0.24 \\
\hline Have been tested for HIV, N (\%) & $23(48)$ & $134(83)$ & 23.77 & $P<0.01$ \\
\hline $\mathrm{HIV+,} \mathrm{N} \mathrm{( \% )} \mathrm{(N=} \mathrm{I57)}$ & $9(43)$ & $82(66)$ & 4.44 & 0.06 \\
\hline AIDS+, $N(\%)(N=91)$ & $\mathrm{I}(\mathrm{II})$ & $24(29)$ & 3.04 & 0.44 \\
\hline HIV treatment, $\mathrm{N}(\%),(\mathrm{N}=9 \mathrm{I})$ & $3(33)$ & $51(62)$ & 2.8 & 0.15 \\
\hline Tested for hepatitis C, N (\%) & $21(44)$ & $104(64)$ & 6.43 & 0.01 \\
\hline Hepatitis C+, N (\%) $(\mathrm{N}=125)$ & $9(43)$ & $71(68)$ & 4.90 & 0.04 \\
\hline Medical composite score (0-I), mean (SD) & $0.39(0.20)$ & $0.43(0.22)$ & 3.40 & 0.54 \\
\hline Body mass index $\left(\mathrm{kg} / \mathrm{m}^{2}\right)$ & $20(2)$ & $21(3)$ & 4.72 & 0.02 \\
\hline \multicolumn{5}{|l|}{ Psychiatric condition in lifetime } \\
\hline Depression, N (\%) & $28(58)$ & $96(59)$ & 0.01 & 1.00 \\
\hline Anxiety, $\mathrm{N}(\%)$ & $41(85)$ & $129(80)$ & 0.41 & 0.25 \\
\hline Memory problems, N (\%) & $35(73)$ & $119(74)$ & 0.01 & 1.00 \\
\hline Hallucination, $\mathrm{N}(\%)$ & $15(31)$ & $63(39)$ & 0.93 & 0.40 \\
\hline Trouble in controlling violent behavior, $\mathrm{N}(\%)$ & $27(56)$ & $88(54)$ & 0.06 & 0.87 \\
\hline Ever treated for psychiatric problems, $\mathrm{N}(\%)$ & $8(17)$ & $53(33)$ & 4.63 & 0.03 \\
\hline Psychiatric composite score $(0-1)$, mean (SD) & $0.24(0.16)$ & $0.17(0.20)$ & 3.63 & 0.40 \\
\hline
\end{tabular}

Abbreviations: AIDS, acquired immunodeficiency syndrome; HIV, human immunodeficiency virus; SD, standard deviation.

$(\mathrm{OR}=3.8 ; 95 \% \mathrm{CI}: 1.9-7.5)$ or other medical services $(\mathrm{OR}=3.1 ; 95 \% \mathrm{CI}: 1.1-8.7)$ increased significantly the probability of HIV treatment.

\section{Discussion}

In this cross-sectional survey from Indonesia, a group of relatively young and well-educated PWID showed that most of them had accessed SAT at least once, especially substitution and traditional/faith-based treatment. Importantly, those who had accessed substitution treatment (methadone or buprenorphine) were more likely to be tested and treated for HIV, compared to those accessing other types of SAT.

In general, the percentage of the utilization of SAT by PWID in this study was higher compared to other studies. ${ }^{7,27}$ The reason for this high percentage can be caused by a different period of time used, and the inclusion of traditional/ 
Table 2 Types of substance abuse treatment modalities ever accessed by people who inject drugs

Substance abuse treatment modalities $(\mathbf{N}=162)$

$\%$

Outpatient detoxification

Residential detoxification

Outpatient substitution

Outpatient drug-free

Residential drug-free

Day care

Psychiatric care

Other medical services

Traditional/faith-based treatment

faith-based treatments in this study. A recent review concluded that information regarding other SAT besides substitution treatment was much less commonly available in many countries, and the inconsistencies and imperfect data on the estimation of PWID population limited the calculation of the coverage of the programs. ${ }^{7}$

The sociodemographic characteristics of the patients in this study were comparable with PWID in other big cities in Indonesia. ${ }^{28}$ They are relatively young men and well educated since almost all (94\%) had completed their senior high school or higher education while only $22.6 \%$ of the citizens in Indonesia have completed senior high school. ${ }^{29}$

Table 3 Associations between types of substance abuse treatment with HIV testing and HIV treatment $(\mathrm{N}=162)$

\begin{tabular}{lll}
\hline $\begin{array}{l}\text { Type of HIV programs } \\
\text { in several types of } \\
\text { substance abuse treatment }\end{array}$ & $\begin{array}{l}\text { Unadjusted OR } \\
\mathbf{( 9 5 \% ~ C I )}\end{array}$ & $\begin{array}{l}\text { Adjusted OR } \\
\mathbf{( 9 5 \% ~ C I )}\end{array}$ \\
\hline HIV testing & & \\
Outpatient detoxification & $2.4(0.9-6.4)$ & $1.1(0.3-3.4)$ \\
Residential detoxification & $9.0(2.1-38.7)^{* *}$ & $4.0(0.8-19.1)$ \\
Outpatient substitution & $6.6(2.9-15.0)^{* *}$ & $5.8(2.5-13.9)^{* *}$ \\
Outpatient drug-free & $2.0(0.6-7.2)$ & $1.1(0.2-4.6)$ \\
Residential drug-free & $3.9(1.6-9.7)^{* *}$ & $3.7(1.4-9.7)^{* *}$ \\
Psychiatric care & $2.7(0.8-9.5)$ & $1.4(0.4-5.7)$ \\
Other medical services & $2.3(0.7-8.1)$ & $1.5(0.3-6.8)$ \\
Traditional/faith-based & $1.6(0.9-3.2)$ & $0.9(0.4-2.0)$ \\
treatment & & \\
HIV treatment & & \\
Outpatient detoxification & $1.7(0.8-3.5)$ & $0.9(0.3-2.2)$ \\
Residential detoxification & $2.0(1.0-4.0)^{*}$ & $0.9(0.4-2.2)$ \\
Outpatient substitution & $3.6(1.9-6.7)^{* *}$ & $3.8(1.9-7.5)^{* *}$ \\
Outpatient drug-free & $2.1(0.8-5.4)$ & $1.9(0.7-5.5)$ \\
Residential drug-free & $1.7(1.0-3.6)^{*}$ & $2.0(0.9-4.1)$ \\
Psychiatric care & $2.1(0.9-4.8)$ & $1.8(0.7-4.9)$ \\
Other medical services & $2.7(1.1-6.6)^{*}$ & $3.1(1.1-8.7)^{*}$ \\
Traditional/faith-based & $1 . I(0.6-2.1)$ & $0.6(0.3-1.3)$ \\
treatment & & \\
\hline
\end{tabular}

Notes: ${ }^{* * p}<0.01 ; * p<0.05$. Day-care treatment was not included in multivariate analyses because one of the blocks in a $2 \times 2$ table was 0 .

Abbreviations: $\mathrm{Cl}$, confidence interval; $\mathrm{HIV}$, human immunodeficiency virus; $\mathrm{OR}$, odds ratio.
Their income was slightly higher than the minimum wage according to the regional standard. ${ }^{30}$ There was no correlation between the choice of SAT modality and the educational level. ${ }^{18}$

PWID who had accessed SAT had more severe drug problems. This possibly can be explained by the finding from another study that stated that PWID accessed treatment only when they were in an emergency or crisis. ${ }^{31,32}$ Alcohol problems were more common among PWID who had never accessed SAT. Although it has been reported that alcohol is associated with risky sexual behavior, ${ }^{33}$ we have found no differences in sexual risk-taking behavior between those who had and had not accessed SAT. This may indicate that other drugs also influence the sexual risk-taking behavior. ${ }^{34}$ The percentage of PWID with injecting and sexual risky behavior was high and in line with other studies. ${ }^{15,35,36}$ However, the frequency of such risky behavior was lower compared to previous studies..$^{37,38}$

We have found that PWID who had accessed SAT had better knowledge on HIV, better access to HIV testing and treatment, hepatitis $\mathrm{C}$ virus testing, and psychiatric treatment. This finding indicates that besides handling drug problems, SAT can be used as an entry point for other harm-reduction programs and health services in Indonesia, similar to studies from other countries. ${ }^{8,9}$ Despite the differences between those that had not accessed SAT, and those who had, psychiatric treatment in general was grossly underutilized. It has been reported before that people who use drugs with psychiatric symptoms rarely want to be referred to the specialized facilities for psychiatric treatment. ${ }^{39}$ It is however important to address this issue, since psychiatric comorbidity can reduce the effectiveness of SAT program..$^{40}$ That is why interventions to increase referral and uptake from/to psychiatric treatment should be addressed. ${ }^{41,42}$

Among PWID who had accessed SAT, substitution treatment (methadone or buprenorphine) was the most widely accessed treatment. The percentage of the utilization of substitution treatment in this study was in line with other national reports. ${ }^{35,36}$ It was shown in this study that the chance to be tested and treated for HIV was most likely in those who had accessed substitution treatment. The integration of HIV programs in substitution treatment indicated effective results, ${ }^{16,43}$ and there were no differences in response to HIV treatment between PWID and the non-PWID groups, ${ }^{44}$ indicating the importance of integrating drug and HIV treatment programs.

The second most widely used SAT modality was traditional/ faith-based treatment. Other studies have reported the frequent 
utilization and satisfaction of traditional/faith-based treatments by PWID and HIV-infected patients. ${ }^{45-47}$ In this study, accessing spiritual/faith-based treatment has no correlation with HIV test and treatment. Spiritual leaders or people providing spiritual/faith-based treatment may be insufficiently informed about medical problems such as blood-borne infections like HIV and hepatitis B/C. Communication and training of providers of spiritual/traditional faith-based treatment services may increase access to HIV care. In addition, faith-based organizations might contribute to daily care for HIV-infected patients. Belief in spiritual healing may also interfere with adherence to ARV treatment, especially due to the belief of traditional/ faith-based treatment leaders. His/her belief regarding ARV treatment will be followed by their disciples. ${ }^{48}$

Faith-based organizations usually operate on the basis of religious missions. In Indonesia, faith-based organizations usually have a large number of followers and/or members capable of dissemination of knowledge throughout the country, ${ }^{12}$ so influencing them to promote HIV testing and treatment could have a large effect. Therefore, despite the debate on the effectiveness of this approach, ${ }^{49}$ close collaboration between drug-related interventions, HIV programs, and traditional/faith-based treatment is required to identify common goals and to ensure successful treatment. ${ }^{48}$

Our present study suffers from the general limitations of a cross-sectional study in a population that is difficult to reach, which raises the question of how representative the samples are. Using RDS, this risk can be minimized with a mathematical model that weights the sample to compensate if the sample was collected in a nonrandom way. ${ }^{50}$ In addition, numerical simulations have shown that the possible bias, even if the seeds are not drawn randomly, is extremely small $(0.3 \%)$ for all sample sizes greater than $200 .{ }^{50}$ Still, some PWID who are not in the social networks with these participants cannot be recruited through RDS. ${ }^{51}$ EuropASI was translated using WHO guidelines and adapted to the Indonesia reality. However, the reliability and validity has not been analyzed. It is not possible to know the numbers accessing certain substance abuse treatment or which combination has the significant association with HIV program since there are too many possible combinations with limited number of sample. By using multivariate analysis and adjusting the OR we can differentiate which type of substance abuse treatment had the highest association with HIV programs. Furthermore, the generalization of the results to the overall condition in Indonesia should be carefully considered, since there were only 49 opioid substitution therapy sites in Indonesia, ${ }^{52}$ mostly distributed in the big cities, while it was estimated that there were more than 219,000 PWID. ${ }^{53}$

\section{Conclusion}

PWID who had accessed SAT had better access to HIV testing, HIV treatment, and other treatment programs compared to those who had not accessed SAT. These findings underline the role of the SAT in HIV prevention and care. The coverage of HIV interventions for PWID may also be improved by introducing HIV programs to other types of SAT services beside substitution treatment, such as traditional/faith-based treatment.

\section{Disclosure}

The authors report no conflicts of interest in this work.

\section{References}

1. Strathdee SA, Hallett TB, Bobrova N, et al. HIV and risk environment for injecting drug users: the past, present, and future. Lancet. 2010;376(9737):268-284.

2. UNAIDS. 2006 Report on the Global AIDS Epidemic: At risk and neglected: four key populations. Geneva, Switzerland: UNAIDS; 2006.

3. Altice FL, Kamarulzaman A, Soriano VV, Schechter M, Friedland GH. Treatment of medical, psychiatric, and substance-use comorbidities in people infected with HIV who use drugs. Lancet. 2010;376(9738): 367-387.

4. Solomon SS, Srikrishnan AK, Celentano DD, et al. The intersection between sex and drugs: a cross-sectional study among the spouses of injection drug users in Chennai, India. BMC Public Health. 2011;11:39.

5. Cohen T, Corbett EL. Test and treat in HIV: success could depend on rapid detection. Lancet. 2011;378(9787):204-206.

6. Slutske WS. Why is natural recovery so common for addictive disorders? Addiction. 2010;105(9):1520-1521; discussion 1524.

7. Mathers BM, Degenhardt L, Ali H, et al. HIV prevention, treatment, and care services for people who inject drugs: a systematic review of global, regional, and national coverage. Lancet. 2010;375(9719):1014-1028.

8. Pollack HA, D'Aunno T. HIV testing and counseling in the nation's outpatient substance abuse treatment system, 1995-2005. J Subst Abuse Treat. 2010;38(4):307-316.

9. Metzger DS, Navaline H. Human immunodeficiency virus prevention and the potential of drug abuse treatment. Clin Infect Dis. 2003;37 Suppl 5: S451-S456.

10. Hser YI, Maglione M, Polinsky ML, Anglin MD. Predicting drug treatment entry among treatment-seeking individuals. $J$ Subst Abuse Treat. 1998;15(3):213-220.

11. Chadda RK, Agarwal V, Singh MC, Raheja D. Help seeking behaviour of psychiatric patients before seeking care at a mental hospital. Int $J$ Soc Psychiatry. 2001;47(4):71-78.

12. Ibrahim K, Haroen H, Pinxten L. Home-based care: a need assessment of people living with HIV infection in Bandung, Indonesia. $J$ Assoc Nurses AIDS Care. 2011;22(3):229-237.

13. National AIDS Commission. Country Report on the follow-up to the Declaration of Commitment on HIV/AIDS (UNGASS): reporting period 2006-2007. Jakarta, Indonesia: National AIDS Commission; 2007.

14. Iskandar $\mathrm{S}$, Basar $\mathrm{D}$, Hidayat $\mathrm{T}$, et al. High risk behavior for HIV transmission among former injecting drug users: a survey from Indonesia. BMC Public Health. 2010;10:472.

15. Pisani E, Dadun, Sucahya PK, Kamil O, Jazan S. Sexual behavior among injection drug users in 3 Indonesian cities carries a high potential for HIV spread to noninjectors. J Acquir Immune Defic Syndr. 2003;34(4):403-406.

16. Achmad YM, Istiqomah AN, Iskandar S, Wisaksana R, van Crevel R, Hidayat $\mathrm{T}$. Integration of methadone maintenance treatment and HIV care for injecting drug users: a cohort study in Bandung, Indonesia. Acta Med Indones. 2009;41(Suppl 1):23-27. 
17. van Laere I, Diana A, van Crevel R, et al. HIV Prevention and Control in Injecting Drug Users in West Java, Indonesia: an evidence-based approach. AIDS Fonds project, final report. Bandung/Nijmegen: RSHS, FK-UNPAD, NISPA, Radboud University, Aids Fonds Program; 2012.

18. Pinxten W, Jong CD, Hidayat T, Istiqomah A, Achmad Y, Raya R. Developing a competence-based addiction medicine curriculum in Indonesia: the training needs assessment. Subst Abuse. 2011;32(2): 101-107.

19. Heckathorn DD, Semaan S, Broadhead RS, Hughes JJ. Extensions of respondent-driven sampling: a new approach to the study of injection drug users aged 18-25. AIDS Behav. 2002;6(1):55-67.

20. McLellan AT, Cacciola JS, Alterman AI, Rikoon SH, Carise D. The Addiction Severity Index at 25: origins, contributions and transitions. Am J Addict. 2006;15(2):113-124.

21. World Health Organization. WHO Collaborative Study on Substitution Therapy of Opioid Dependence and HIV/AIDS: General Protocol. 2008. Available from: http://www.who.int/substance_abuse/research_tools/ translation/en/print.html. Accessed May 1, 2008.

22. Addiction Severity Index: Manual and Question by Question Guide. Treatment Research Institute. 2008. Available from: http://www.tresearch org/resources/manuals/ASIQbyQGuide.pdf. Accessed May 1, 2008.

23. Blanken P, Hendriks V, Pozzi G, et al. European Addiction Severity Index (EUROPASI): Cost A6: A guide to training and administering EUROPASI interviews; Addiction Research Institute Rotterdam (IVO): 1994.

24. McGahan PL, Griffith JA, Parente R, McLellan AT. Addiction Severity Index: Composite Scores Manual. 1986. Available from: http://www. tresearch.org/resources/compscores/CompositeManual.pdf. Accessed May 1, 2008.

25. Fry CL, Lintzeris N. Psychometric properties of the Blood-borne Virus Transmission Risk Assessment Questionnaire (BBV-TRAQ). Addiction. 2003;98(2):171-178

26. Hinduan ZR, Kesumah N, Iskandar Z, van Crevel R, Alisjahbana B, Hospers HJ. Characteristics of subjects counseled and tested for HIV in an Indonesian hospital; factors associated with HIV-status and CD4 cell-count. Acta Med Indones. 2009;41 Suppl 1:12-17.

27. Todd CS, Abed AM, Scott PT, Safi N, Earhart KC, Strathdee SA A cross-sectional assessment of utilization of addiction treatment among injection drug users in Kabul, Afghanistan. Subst Use Misuse. 2009;44(3):416-430.

28. Ministry of Health, National AIDS Committee, United States Agency for International Development, Americans for Safe Access, Family Health International. HIV/STI Integrated Biological Behavioral Surveillance (IBBS) among Most-at-Risk Group (MARG) in Indonesia, Jakarta, Indonesia: Ministry of Health, National AIDS Committee, Family Health International; 2007.

29. Hartono B, Kusumobroto BS. Departemen Kesehatan Republik Indonesia: Profil Kesehatan Indonesia 2006. Jakarta, Indonesia: Departemen Kesehatan Republik Indonesia; 2007.

30. UPAH MINIMUM PROPINSI (UMP) 2008. [regional minimum wage] Available from: http://www.pajak.net/blog/peraturan/ump2008.pdf. Accessed October 17, 2010.

31. Morrison A, Elliott L, Gruer L. Injecting-related harm and treatmentseeking behaviour among injecting drug users. Addiction. 1997;92(10): 1349-1352.

32. Neale J, Sheard L, Tompkins CN. Factors that help injecting drug users to access and benefit from services: A qualitative study. Subst Abuse Treat Prev Policy. 2007;2:31.

33. Arasteh K, Des Jarlais DC, Perlis TE. Alcohol and HIV sexual risk behaviors among injection drug users. Drug Alcohol Depend. 2008;95(1-2):54-61.

34. Rawson RA, Gonzales R, Pearce V, Ang A, Marinelli-Casey P, Brummer J. Methamphetamine dependence and human immunodeficiency virus risk behavior. J Subst Abuse Treat. 2008;35(3):279-284.
35. Heriawan R, Ahnaf A, Anwar J, et al. Behavioral Surveillance Survey (BSS) Result in Indonesia 2004-2005. Jakarta, Indonesia: Indonesian Board of Statistics; 2005.

36. Thorne C, Ferencic N, Malyuta R, Mimica J, Niemiec T. Central Asia: hotspot in the worldwide HIV epidemic. Lancet Infect Dis. 2010;10(7):479-488.

37. Lawrinson P, Ali R, Buavirat A, et al. Key findings from the WHO collaborative study on substitution therapy for opioid dependence and HIV/AIDS. Addiction. 2008;103(9):1484-1492.

38. Tucker T, Fry CL, Lintzeris N, et al. Randomized controlled trial of a brief behavioural intervention for reducing hepatitis $\mathrm{C}$ virus risk practices among injecting drug users. Addiction. 2004;99(9):1157-1166.

39. Kimber J, Mattick RP, Kaldor J, van Beek I, Gilmour S, Rance JA. Process and predictors of drug treatment referral and referral uptake at the Sydney Medically Supervised Injecting Centre. Drug Alcohol Rev. 2008;27(6):602-612.

40. Gelkopf M, Weizman T, Melamed Y, Adelson M, Bleich A. Does psychiatric comorbidity affect drug abuse treatment outcome? A prospective assessment of drug abuse, treatment tenure and infectious diseases in an Israeli methadone maintenance clinic. Isr J Psychiatry Relat Sci. 2006;43(2):126-136.

41. Kessler RC, Brown RL, Broman CL. Sex differences in psychiatric help-seeking: evidence from four large-scale surveys. J Health Soc Behav. 1981;22(1):49-64.

42. Biddle L, Gunnell D, Sharp D, Donovan JL. Factors influencing help seeking in mentally distressed young adults: a cross-sectional survey. Br J Gen Pract. 2004;54(501):248-253.

43. Degenhardt L, Mathers B, Vickerman P, Rhodes T, Latkin C, Hickman M. Prevention of HIV infection for people who inject drugs: why individual, structural, and combination approaches are needed. Lancet. 2010;376(9737):285-301.

44. Wisaksana R, Indrati AK, Fibriani A, et al. Response to first-line antiretroviral treatment among human immunodeficiency virus-infected patients with and without a history of injecting drug use in Indonesia. Addiction. 2010;105(6):1055-1061.

45. Manheimer E, Anderson BJ, Stein MD. Use and assessment of complementary and alternative therapies by intravenous drug users. Am J Drug Alcohol Abuse. 2003;29(2):401-413.

46. Furler MD, Einarson TR, Walmsley S, Millson M, Bendayan R. Use of complementary and alternative medicine by HIV-infected outpatients in Ontario, Canada. AIDS Patient Care STDS. 2003;17(4): $155-168$.

47. Hsiao AF, Wong MD, Kanouse DE, et al. Complementary and alternative medicine use and substitution for conventional therapy by HIV-infected patients. J Acquir Immune Defic Syndr. 2003;33(2):157-165.

48. Wanyama J, Castelnuovo B, Wandera B, et al. Belief in divine healing can be a barrier to antiretroviral therapy adherence in Uganda. AIDS. 2007;21(11):1486-1487.

49. Avants SK, Warburton LA, Margolin A. Spiritual and religious support in recovery from addiction among HIV-positive injection drug users. J Psychoactive Drugs. 2001;33(1):39-45.

50. Salganik MJ, Heckathorn DD. Sampling and estimation in hidden populations using respondent driven sampling. Sociol Method. 2004;34:193-240.

51. Trotter RT II, Bowen AM, Potter JM Jr. Network models for HIV outreach and prevention programs for drug users. NIDA Res Monogr. 1995;151:144-180.

52. World Health Organization. A Strategy to Halt and Reverse the HIV Epidemic Among People Who Inject Drugs in Asia and the Pacific 2010-2015. Geneva, Switzerland: WHO, UNAIDS, UNODC, The Global Fund, ANPUD; 2010.

53. Mathers BM, Degenhardt L, Phillips B, et al. Global epidemiology of injecting drug use and HIV among people who inject drugs: a systematic review. Lancet. 2008;372(9651):1733-1745. 


\section{Publish your work in this journal}

The Journal of Multidisciplinary Healthcare is an international, peerreviewed open-access journal that aims to represent and publish research in healthcare areas delivered by practitioners of different disciplines. This includes studies and reviews conducted by multidisciplinary teams as well as research which evaluates the results or conduct of such teams or

healthcare processes in general. The journal covers a wide range of areas and welcomes submission from practitioners at all levels, from all over the world. The manuscript management system is completely online and includes a very quick and fair peer-review system. Visit http://www.dovepress.com/testimonials.php to read real quotes from published authors.

Submit your manuscript here: http://www.dovepress.com/journal-of-multidisciplinary-healthcare-journal 